\title{
Principles of electricity metering in networks with non-liner load
}

\author{
Tamara Pudkova* and Alexey Bardanov \\ Saint-Petersburg Mining University, 2, 21 st Line of Vasilevskiy Island, St. Petersburg 199106, Russian Federation
}

\begin{abstract}
The existing approach to electricity metering, which underlies the formation of payment for consumed electricity, has a significant drawback. It can be correctly used in systems with a sinusoidal symmetrical mode, but needs to be improved in other network modes. The article defines indicators that numerically reflect the effect of distortions on the modes of distribution electric networks, as well as indicators that take into account consumed inactive power (by analogy with reactive power in a sinusoidal mode) when paying electricity bills to an electricity supplier. The proposed principles of electricity consumption metering includes the influence of such indicators as the spectral composition of voltage and current, the ratio of linear and nonlinear loads of consumers, as well as the influence of the topology of the electric network.
\end{abstract}

\section{Introduction}

The concept of "reactive power" is applicable only to electric networks with a sinusoidal symmetrical mode [1-5].

Non-sinusoidal network operation occurs when there is a non-linear load, which is represented by a variety of technical means and equipment [6-8]. As a result, higher harmonics of current and voltage appear in the electric network of the electrical complex[9-11], the influence of which must be taken into account in non-sinusoidal network operation modes [12-15]. This leads to attempts to replace the concept of "reactive power" with others, which could reflect the influence of higher harmonics on power consumption modes and its accounting [16-18]. At the same time, counters with built-in microprocessors are still used to pay for reactive energy, into which various "measuring" equations are embedded [19, 20]. Among these equations, the following are most widely used:

$$
Q^{1}=U^{1} I^{1} \sin \varphi^{1}
$$

where $U^{l}, I^{l}, \sin \varphi^{l}-$ voltage, current and phase difference between them at the first harmonic, resp.

$$
Q=\sqrt{S^{2}-P^{2}}
$$

where $S=U I$ - apparent power; $U, I-$ effective values of voltage and current, resp.; $P$ - active power.

Only the fact that the consumer is offered various expressions for determining reactive power, speaks of the incorrectness of accounting for reactive energy.

It follows from the above that at least two problems have not yet been solved:
1) Not defined indicators that reflect numerically the effect of distortion on the modes of distribution of electrical networks;

2) The indicators taking into account the consumed inactive power (by analogy with the reactive in sinusoidal mode) when calculating for electricity with the electricity supplier are not defined. From here follows the relevance of the topic raised in the article.

\section{Methods}

Before presenting a solution to the first problem, we analyze the most correct indicator, the value of which should be equal to unity.

$$
K_{M}=\frac{P_{\sum}}{S}=\frac{P_{\Sigma}}{U I},
$$

where $P_{\Sigma}$ - total active power including higher harmonics.

$$
P_{\sum}=\sum_{i=1}^{N} P^{(i)}
$$

where $P(i)$ - active power of i-es harmonic including fundamental harmonic.

Solving the second problem, first of all, it is necessary to analyze the following situation: why and what for energy supplying organizations are interested in paying for reactive power?

When generating electricity for the consumption of reactive power of the load, no primary energy is spent. It follows that reactive power causes only an increase in current in the line and windings of the generator. Thus, with a high degree of probability it can be argued that reactive power was and remains an indirect sign of the

\footnotetext{
* Corresponding author: Pudkova TV@ pers.spmi.ru
} 


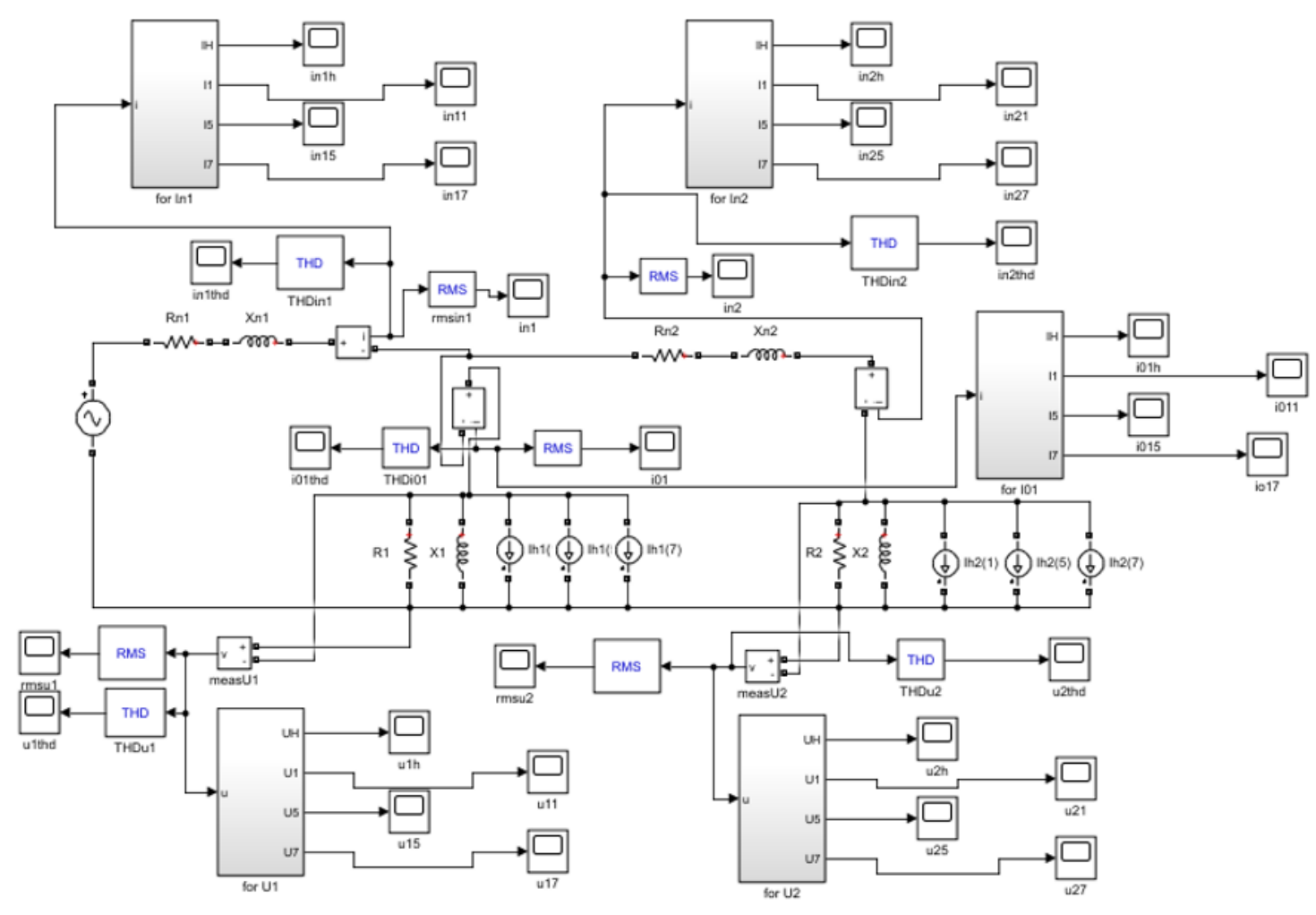

Fig. 1. The model of the studied distribution network.

presence of an inactive current (or reactive current at each higher harmonic), which reduces the line throughput, the load of the active power generator and the cost of examining the transmission line.

The model of the studied distribution network is presented in Figure 1.

The model includes a voltage source $\mathrm{U}$, active and inductive resistance of the lines $\mathrm{R} 11, \mathrm{R} 12, \mathrm{X} 11, \mathrm{X} 12$. The load is represented by a parallel connection of active and inductive resistances, including sources of fundamental and higher harmonics (1, 5.7). If necessary, model parameters can be adjusted. The number of harmonics generated by the current sources at each load can also vary.

On each line, a set of measuring instruments is installed that record the THD values for current and voltage, their RMS values. In addition, for detailed detailing of distortions, there is a block that reflects the phase and amplitude values of each harmonic separately.

\section{Results and Discussion}

The solution to the first problem.

As the conducted research showed, the value of $K_{M}=$ 1 is not the only and sufficient condition for the optimality of the transmission of electricity. This is explained by an increase in active power losses with an increase in the order of harmonics (Fig. 1), which are determined by the formula:

$$
\Delta P=I^{2} R=I_{1}^{2}\left(1+T H D_{1}^{2}\right) \cdot R,
$$

From the graph it follows that the effective value of the total current can be expressed through a harmonic series as follows:

$$
I^{2}=\sum_{i=1}^{N} I_{a}^{(i) 2}+\sum_{i=1}^{N} I_{p}^{(i) 2}=I_{a}^{(1) 2}+\sum_{i=2}^{N} I_{a}^{(i) 2}+\sum_{i=1}^{N} I_{p}^{(i) 2},
$$

where $I a^{(l)}$ - active current of fundamental harmonic; $I a^{(i)}, I p^{(i)}$ - active and reactive current of $i$-es harmonic.

The value of $K_{M}=1$ can be obtained under conditions:

$$
\sum_{i=1}^{N} I_{p}^{(i) 2}=0
$$

or

$$
\sum_{i=2}^{N} I_{a}^{(i) 2}=0, \sum_{i=1}^{N} I_{p}^{(i) 2}=0
$$

Based on the real situation of reactive power compensation, condition (6) is possible only if a rather complicated active filter configuration is used. In other cases, the fulfillment of this condition is impossible.

From this condition, the developed condition follows, which can be represented as follows:

$$
\sum_{i=2}^{N} I_{a}^{(i) 2}=0, \sum_{i=1}^{N} I_{p}^{(i) 2}=0 \rightarrow \min .
$$

The solution to the second problem.

For the correct accounting of electricity, it is necessary to take into account the influence of distortions as follows: 


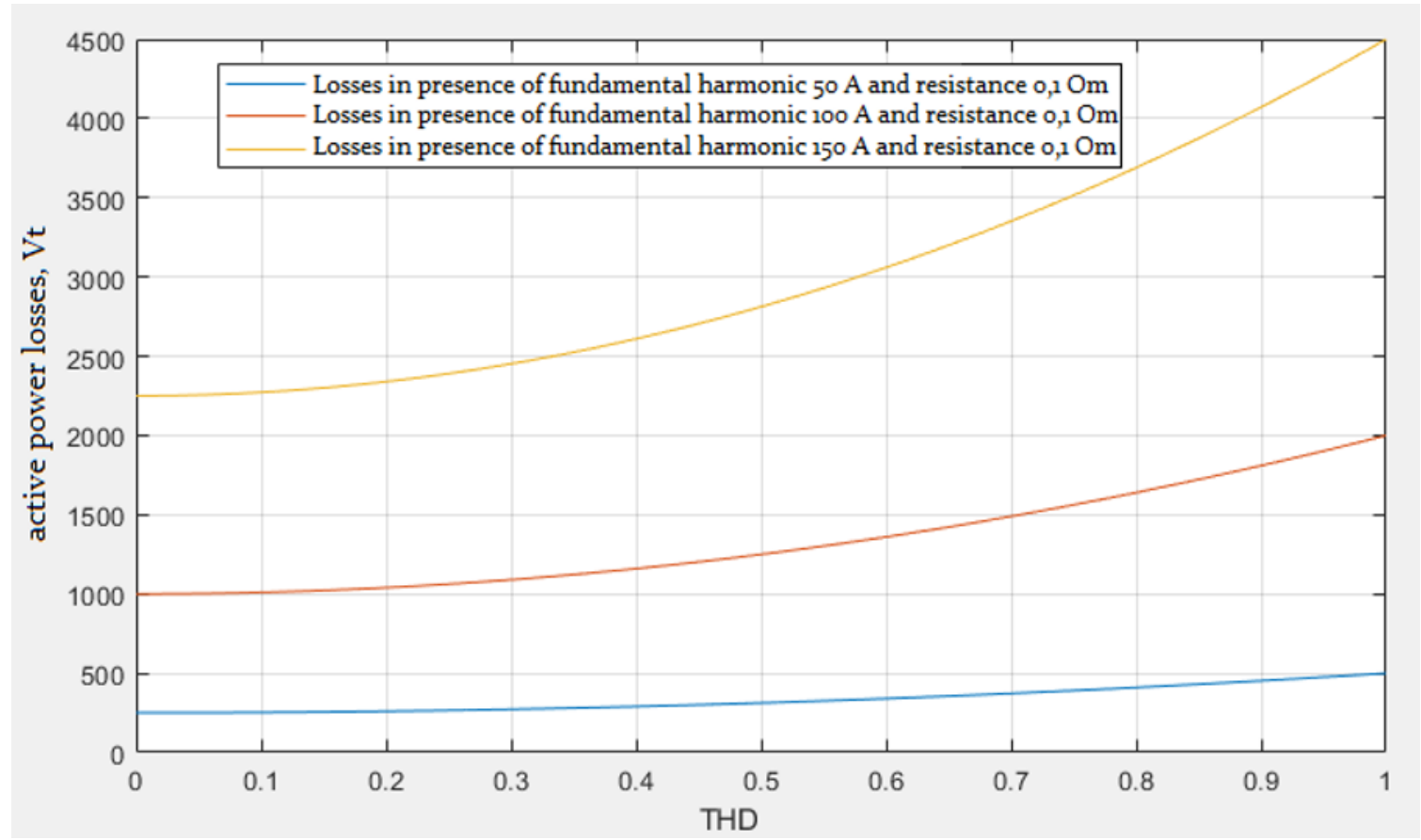

Fig. 2. Losses in presence of fundamental harmonic.

$$
\begin{aligned}
& V_{1}=\int_{0}^{t} \sqrt{I^{2}-I_{a}^{(1) 2} d t}, \\
& V_{2}=\int_{0}^{t} I^{2}-I_{a}^{(1) 2} d t .
\end{aligned}
$$

Let's $I=100 A, I a^{(l)}=0-1$, then the curves of changes in $V 1$ and $V 2$ presented in Figure 4.2 determine the costs of inactive energy. Graphs are presented in relative units.

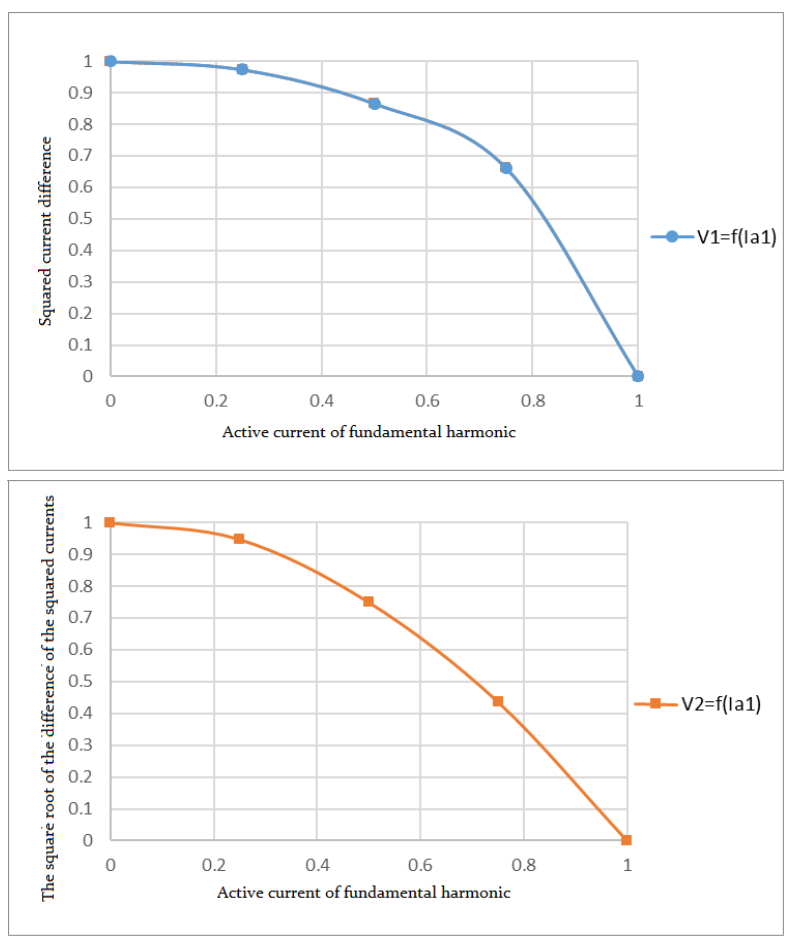

Fig. 3. The dependence of the share of inactive energy costs on the active current at the fundamental.
The first version gives an advantage to those who significantly reduce the current difference to the ratio $I / I_{a}^{(1)}=0.5$, and the second version can significantly reduce the cost of inactive power after $\left.I / I_{a}^{(1)}\right\rangle 0.5$.

Thus, the choice of calculating electricity consumption for $V 1$ and $V 2$ should be made by the tariff committee.

\section{Conclusions}

Payment for active energy is not in doubt and complies with generally accepted practice and physics of generation, as well as transmission of electricity. Based on the foregoing, payment for reactive energy by meters seems incorrect. Payment for the full current (or a component of power directly proportional to it) can be correct, which can be realized,

For instance, by an integrated current meter. In this case, two options are proposed for calculating the indicator that determines the costs in the process of "generation-transmission-consumption" of electricity, which reflects the essence of energy accounting in the presence of distortions and directly includes the effect of harmonics on active power consumption.

\section{References}

1.J. Arrillaga, Energy, and Machines (2017)

2.A. E. Emanuel (2010)

3.D. Sharon, IEEE Trans. Instrum. Meas. (1996)

4.L. S. Czarnecki, IEE Proc. B Electr. Power Appl. (1992)

\section{S. Fryze, Prz. Elektrot (1931)}


6. V. Y. Frolov and A. I. Toropchin, Tech. Phys. Lett. (2015)

7.H. Hafezi and R. Faranda, IEEE Trans. Power Electron. (2018)

8. N. V. Obraztsov, V. Y. Frolov, V. E. Popov, D. I. Subbotin, and A. V. Surov, in Journal of Physics:

Conference Series (2018)

9. IEEE Trans. Sustain. Energy (2016)

10. N. Tashakor, H. Samet, and A. Sahebi, in 2016 24th Iranian Conference on Electrical Engineering, ICEE (2016)

11. I. Masoudipour and H. Samet, in IET Conference Publications (2013)

12. H. Lev-Ari and A. M. Stankovic, in 12th Conference-Seminar: International School on Nonsinusoidal Currents and Compensation, ISNCC 2015 - Conference Proceedings (2015)

13. H. Lev-Ari and A. M. Stanković, IEEE Trans. Power Syst. (2006)

14. V. Y. Koptev, A. V. Kopteva, and D. A. Poddubniy, in Proceedings of the 2019 IEEE Conference of Russian Young Researchers in Electrical and Electronic Engineering, ElConRus (2019)

15. K. Vostrov, V. Frolov, and E. Safonov, in 22nd Symposium on Physics of Switching Arc, (2017)

16. H. Ye, G. Y. Li, and B. H. Juang, IEEE Wirel. Commun. Lett. (2018)

17. I. Murashov, V. Frolov, M. Korotkikh, and L. Ushomirskaya, in MATEC Web of Conferences (2018)

18. A. A. Belitskiy, I. I. Rastvorova, and O. V. Denisova, in Proceedings of the 2018 IEEE Conference of Russian Young Researchers in Electrical and Electronic Engineering, ElConRus (2018)

19. D. Jeltsema, T. Voss, and H. Mala, in Proceedings of International Conference on Harmonics and Quality of Power, ICHQP (2018)

20. L. S. Czarnecki, in Proceedings of International Conference on Harmonics and Quality of Power, ICHQP (2018) 